\title{
Remediation of Oil Polluted Well in Baruwa Area of Lagos State with Potassium Permanganate
}

Oluwalope MT*, Aramide OT and Ajayi 00

Department of Chemistry, Federal University of Technology Akure (FUTA), Akure, Nigeria

\begin{abstract}
Crude oil spills on soil, leakages from pipelines, underground and surface fuel storage tanks and careless disposal and mismanagement of waste and other petroleum by-products of the society, constitute the major sources of petroleum contamination in our environment. The estimated 65,000 people of Baruwa own about 350 hand dug wells for domestic water supply; more than 200 of these wells are at present, under lock and key because of the oil seepage from leaking underground NNPC (Nigerian National Petroleum Corporation) pipeline. Water samples were collected from seven hand dug wells (Jakande, Kamilla, Baale, Shodeinde, Oyewole, Lasunferanmi and Ajayi). Jakande was the control while the rest were the contaminated wells. All the wells contained TPH and Lasunferanmi had the highest TPH while Jakande had the lowest. It was observed that after the application of KMnO4 to the water samples from the oil polluted wells, the $\mathrm{TPH}$ concentration reduced significantly in the laboratory. Also, the kinetics of the remediation done for the reactions followed a second order reaction with a proof of linearity of the graphs and R2 value close to unity.
\end{abstract}

Keywords: Chemical remediation; Oil polluted wells; Potassium permanganate

\section{Introduction}

Water is a constant gift of nature that defines peace in life. It remains a veritable endowment of nature necessary for life sustenance of plants and animals [1]. Water support all forms of biological resources (plant and animal life) and are normally obtained from two major natural sources which are surface water (water bodies) such as rivers, streams, fresh water lakes and ground water (geological water) such as borehole and well water $[2,3]$.

Oil is a general term used to denote liquid petroleum products which mainly consists of hydrocarbons. The release of oil into the natural environment is termed oil spill. The extraction, refining, transportation and storage of oil are accompanied by seepages and spills by operations or accidents. Deliberate act such as sabotage, oil bunkering, lack of maintenance of engineering equipment, tanker accidents causes oil spill. Oil spill can also occur through natural disasters like hurricane and earthquake, movement of tectonic plate and inadequate trap system [4].

There has been a significantly higher rate (spills per length of pipeline) of serious pipeline spills in the Niger Delta than in developed countries such as the USA, beyond that accounted for by sabotage. This, and other evidence, suggests that oil companies operating in the Niger Delta are not employing internationally recognized standards to prevent and control pipeline oil spills [5]. According to Opukri and Ibaba [6], environmental degradation issues are of tropical concern to communities in the Niger Delta as it is a major cause of productivity losses. The dominant view blames oil production and its attendant consequences for the declining productivity of local economies that are mainly based on fisheries and agriculture [7]. The literature on the Niger Delta highlights poverty, unemployment, underemployment, proletarianisation, and rural urban migration as the consequences [6]. The collapse of the local economies, induced by oil spillages, gas flaring and other activities of the oil industry had displaced many from their occupations, without providing viable alternatives.

\section{Statement of the problem}

Baruwa is a host community of NNPC pipeline which runs through the community from Mosinmi oil depot to Ejigbo oil facility.

The community had their wells and borehole contaminated with petroleum hydrocarbon due to oil leaks from the pipeline as a result of the aged and rusted pipeline. In the same vein, about 500,000 people have been deprived of drinkable water since 1996 because of the oil seepage from leaking underground NNPC (Nigerian National Petroleum Corporation) pipeline. According to Baale and the community residents, the residents have suffered persistent catarrh, irritation of the airways, wateriness, discoloration of the cornea of the eyes, skin rashes, and dermatitis [8].

\section{Aims of the research}

This research is concerned with the remediation of oil water samples from Baruwa Community in Lagos state by the application of potassium permanganate and the evaluation of the kinetics of remediation.

\section{Materials and Methods}

\section{The study area}

Baruwa community is located in the Alimosho Local Government of Lagos State. It lies between latitudes 6"36" 12"and longitude 3"16'. It is drained by Lagos lagoon, Badagry creek and Lekki lagoon which runs into the lagoon. Geographically, the community lies on a poorly sorted coastal sedimentary plain and recent alluvial deposit in Nigeria. The Local Council is richly blessed with arable landmass of about 57.621 $\mathrm{km}^{2}$ and it is surrounded by rivers Owa and Oponu which are suitable for navigation, fishing and tourism purposes.

Groundwater in Baruwa is about $25 \mathrm{~m}$ below ground surface in wells. The wells are between $0.75 \mathrm{~m}$ and $2.00 \mathrm{~m}$ in diameter. The wells within the pilot scheme area are about $1.2 \mathrm{~m}$ in diameter. There are more than 200 hand dug domestic water supply wells contaminated with floating petroleum product of varying thickness $(0.20 \mathrm{~m}$ to $0.65 \mathrm{~m})$ at this site because of oil seepage from leaking underground NNPC (Nigerian

*Corresponding author: Oluwalope MT, Department of Chemistry, Federal University of Technology Akure (FUTA), Akure, Nigeria, Tel: +2348038622658; E-mail: sirmantee@yahoo.com

Received August 24, 2017; Accepted September 05, 2017; Published September 11,2017

Citation: Oluwalope MT, Aramide OT, Ajayi OO (2017) Remediation of Oil Polluted Well in Baruwa Area of Lagos State with Potassium Permanganate. J Environ Anal Chem 4: 212. doi: $10.41722380-2391.1000212$

Copyright: (c) 2017 Oluwalope MT, et al. This is an open-access article distributed under the terms of the Creative Commons Attribution License, which permits unrestricted use, distribution, and reproduction in any medium, provided the original author and source are credited. 
National Petroleum Corporation) pipeline. One well was selected for study, Ajayi's well and this represents one of the most polluted wells in Baruwa community.

\section{Sample collection and preservation}

The water samples for this study were collected from six wells within the pilot scheme and one well outside the pilot scheme as control in Baruwa area of Lagos State. Plastic bottles pretreated with dilute sulfuric acid and thoroughly rinsed with distilled water were used to
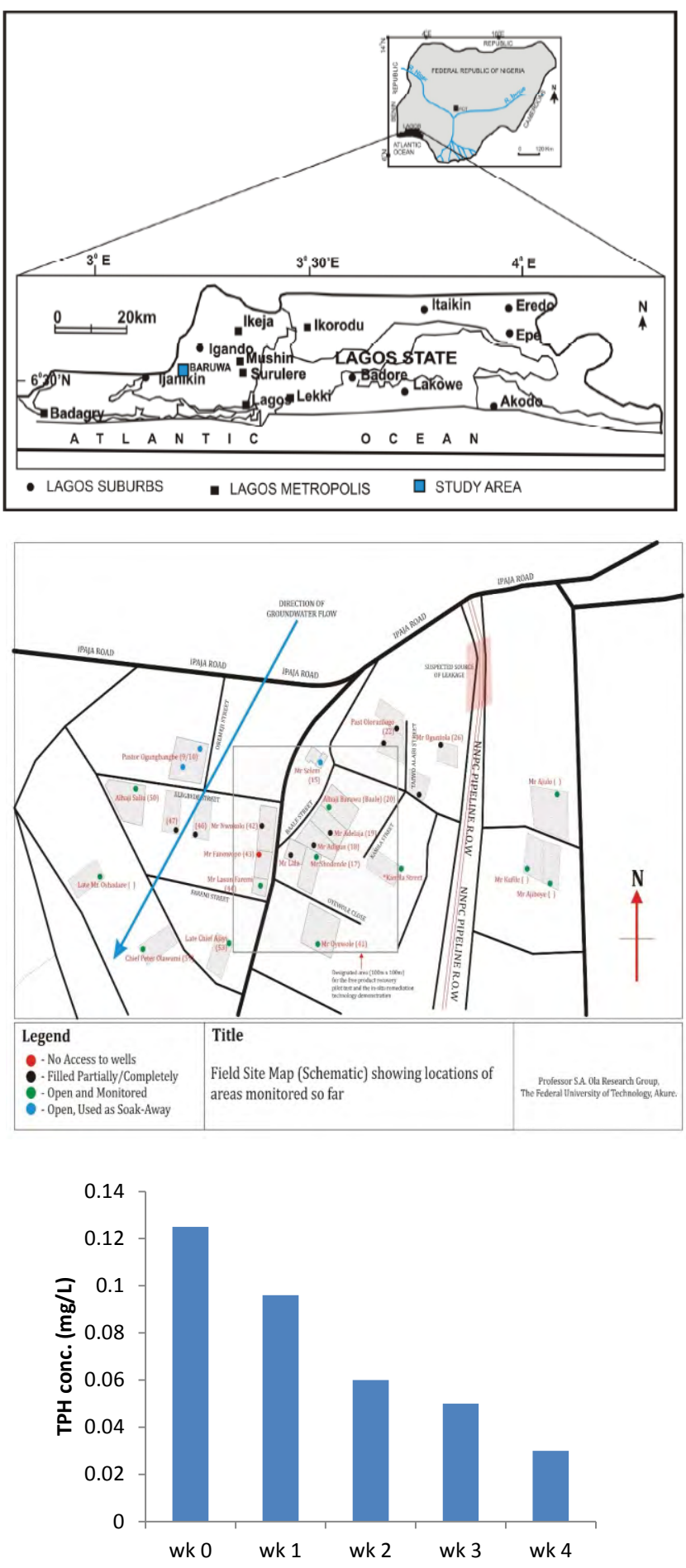

Figure 1.1: Bar chart of remediation of Oyewole with $\mathrm{KMnO}_{4}$. collect samples for Total Petroleum Hydrocarbon (TPH) and $2 \mathrm{ml}$ of concentrated sulphuric acid was added to each litre of the sample as preservative. The samples were stored in the refrigerator at $4^{\circ} \mathrm{C}$ prior to analysis [9].

\section{Methods}

\section{Determination of total petroleum hydrocarbon solvent extraction}

$50 \mathrm{ml}$ of samples was collected into $250 \mathrm{ml}$ separating flask. $30 \mathrm{ml}$ of Dichloromethane (DCM) was added into the flask. The flask was shaken and pressure released at intervals. The sample was allowed to stand for few minutes and two layers were formed in the flask. The lower layer (extract) of the sample was collected into a beaker through a filter paper that was filled with anhydrous sodium sulphate $\left(\mathrm{Na}_{2} \mathrm{SO}_{4}\right)$. The extraction was done in three batches.

\section{Extracts clean-up and TPH analysis}

Column preparation was carried out by inserting glass cotton into the column. Silica gel was dissolved with DCM to form slurry and the slurry was added into the column. Anhydrous $\mathrm{Na}_{2} \mathrm{SO}_{4}$ was also added and the extract was transferred into the column. The eluted sample was collected in a beaker below the column. This was then concentrated with a Rotary evaporator and then $5 \mathrm{ml}$ of $\mathrm{n}$-hexane was added and the solvent was left to evaporate to dryness. Thus, the TPH was calculated below:

Total Petroleum Hydrocarbon $(\mathrm{TPH}) \mathrm{mg} / \mathrm{L}=(\mathrm{A}-\mathrm{B} \times 1000) /$ Sample Volume (ml)

where, $A=$ Total gain in weight for experimental sample (mg); $\mathrm{B}=\mathrm{Gain}$ in weight for blank $(\mathrm{mg})$

\section{Procedure for remediation}

The Total Petroleum Hydrocarbon (TPH) of each of the water samples were first determined to ascertain the initial concentration. Then $0.01 \mathrm{M}^{\text {of }} \mathrm{KMnO}_{4}$ solution was prepared and used for treatment. The molarities was applied to $250 \mathrm{ml}$ of the the samples: Jakande (control), Kamilla, Baale, Shodeinde, Oyewole, Lasunferanmi, and Ajayi, first at $4 \mathrm{ml}$ each for the first and second week, then $2 \mathrm{ml}$ each in the third and fourth week and the TPH concentration was evaluated every week using gravimetric analysis. The volume of sample evaluated for TPH every week was $50 \mathrm{ml}$ each.

\section{Determination of TPH and kinetics of remediation}

In Table 1, TPH ranged from 0.119 to $2.54 \mathrm{mg} / \mathrm{L}$. Jakande (control) had the least concentration while Lasunferanmi had the highest concentration. Shodeinde and Oyewole had 0.544 and $0.466 \mathrm{mg} / \mathrm{L}$ respectively. In Figures 1.1 and 1.5, the remediation of Oyewole and Kamilla followed a trend that showed a slow and gradual decrease in TPH concentration at every week of the oxidation process. While in Figure 1.3, there was a very drastic decrease in the TPH value from 2.54 $\mathrm{mg} / \mathrm{L}$ to $0.3 \mathrm{mg} / \mathrm{L}$ in the first week, while a slow and gradual decrease was observed in other weeks. Similarly, in Figure 1.7, there was also a sharp decrease in TPH value from $0-1$ week while in week 2 , the value increased but decreased again in week 3 and 4 .

Kinetics of permanganate oxidative method was investigated for its order of reaction. The concentration of total petroleum hydrocarbon left was plotted against time as represented in Figures 1.2, 1.4, 1.6 and 1.8. It was observed that TPH decreased with time as reaction progressed. This was a strong indication that there was an interaction between 
total petroleum hydrocarbon molecules and the reacting species of the treatment solution in the permanganate-oxidative method employed in the study. The equation $1 /(\mathrm{TPH}$ left $)=\mathrm{Kt}+1 /$ (initial TPH) established the relationship between TPH concentration and time for a secondorder reaction, where $\mathrm{t}=$ time and $\mathrm{K}=$ rate constant. Plot of $1 /$ (TPH left) against time gave a graph of good linearity confirming second order reaction kinetics for the permanganate-oxidation method. The graph of Bar Oyewole and Kamilla looked exactly the same, their $\mathrm{R}^{2}$ values were close as well as their $\mathrm{t}_{1 / 2}: 0.912$ and 0.937 , and 1.33 and 1.15 week respectively. This was shown in Figures 1.2 and 1.5. However, in Figures 1.4 and 1.8, the $\mathrm{t}_{1 / 2}$ of Lasunferanmi and Shodeinde were 0.41 and 0.96 week respectively. This implied that half of the TPH was already decomposed within few days- less than a week. This was a very good result because the half-life should be shorter in the early stage

\begin{tabular}{|c|c|}
\hline Site & TPH $(\mathbf{m g} / \mathbf{L})$ \\
\hline Jakande & 0.119 \\
\hline Kamilla & 0.271 \\
\hline Baale & 0.174 \\
\hline Shodeinde & 0.544 \\
\hline Oyewole & 0.125 \\
\hline Lasunferanmi & 2.54 \\
\hline Ajayi & 0.466 \\
\hline
\end{tabular}

Table 1: Determination of TPH of the wells before remediation.

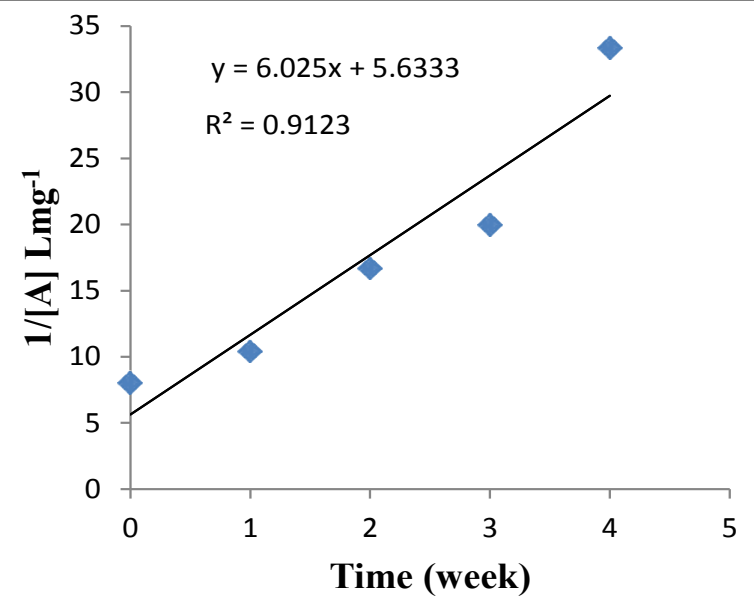

Figure 1.2: Graph of second order reaction of Oyewole.

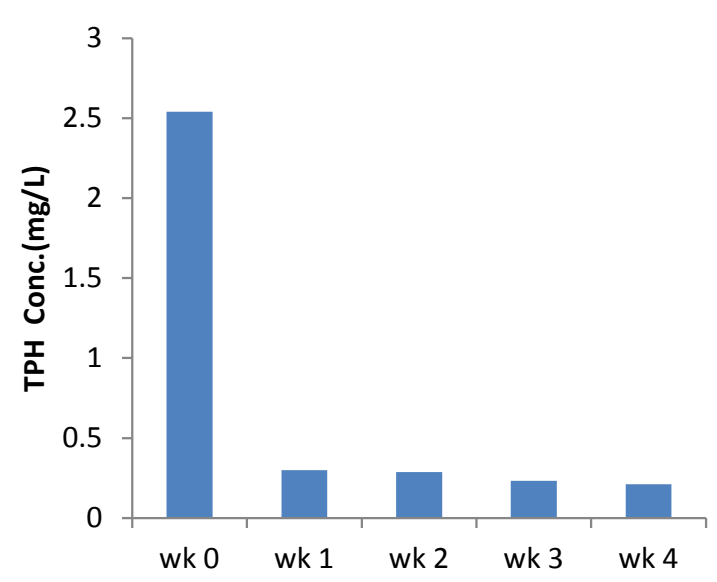

Figure 1.3: Bar chart of remediation of Lasunferanmi with $\mathrm{KMnO}_{4}$.

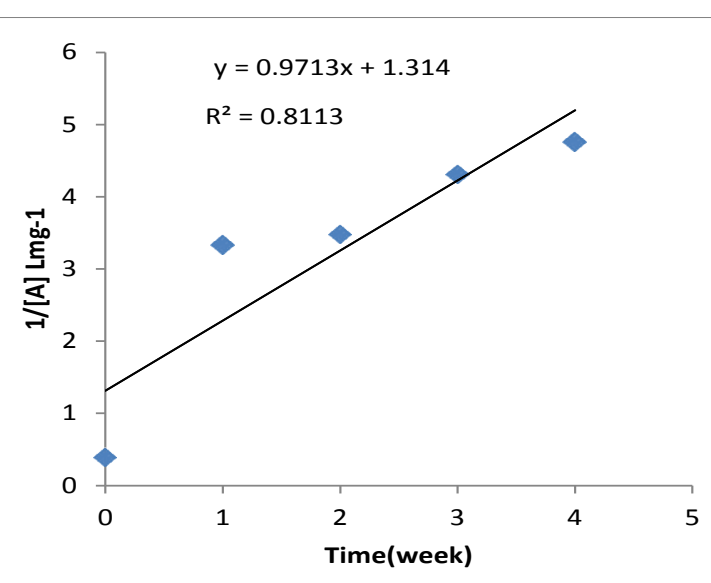

Figure 1.4: Graph of second order reaction of Lasunferanmi.

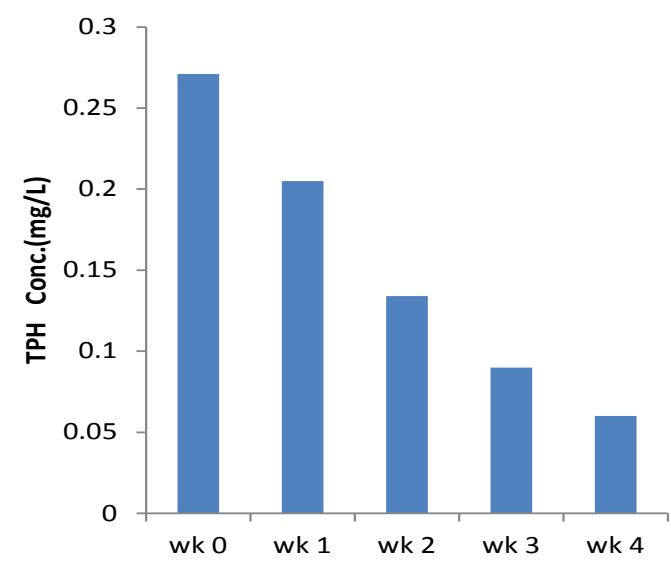

Figure 1.5: Bar chart of remediation of Kamilla with $\mathrm{KMnO}_{4}$.

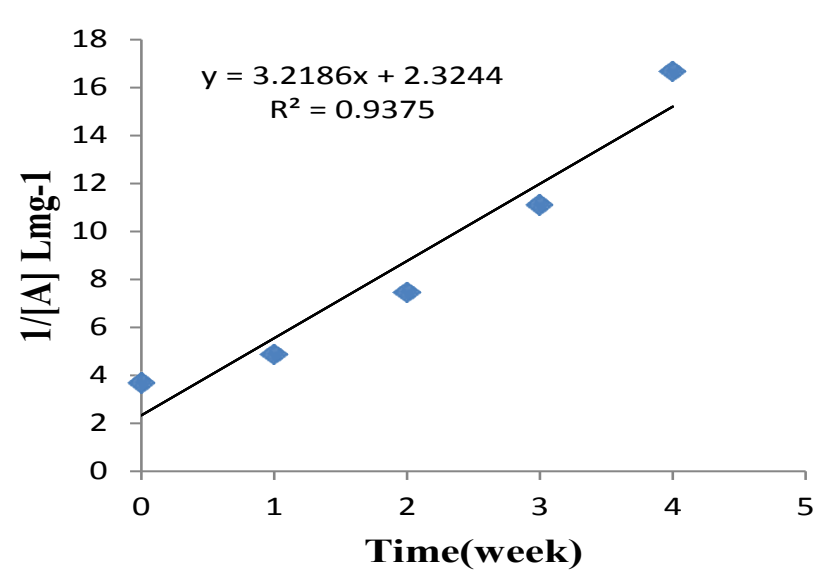

Figure 1.6: Graph of second order reaction of Kamilla.

of the reaction when more of the reactant molecules were present to collide with each other.

$\mathrm{R}^{2}=0.912, \mathrm{~K}=6.025$ week $^{-1}$

[A exp.] $=0.125 \mathrm{mg} / \mathrm{L}$, [A cal.] $=0.178 \mathrm{mg} / \mathrm{L}$

$\mathrm{T}_{1 / 2}=1.33$ week 


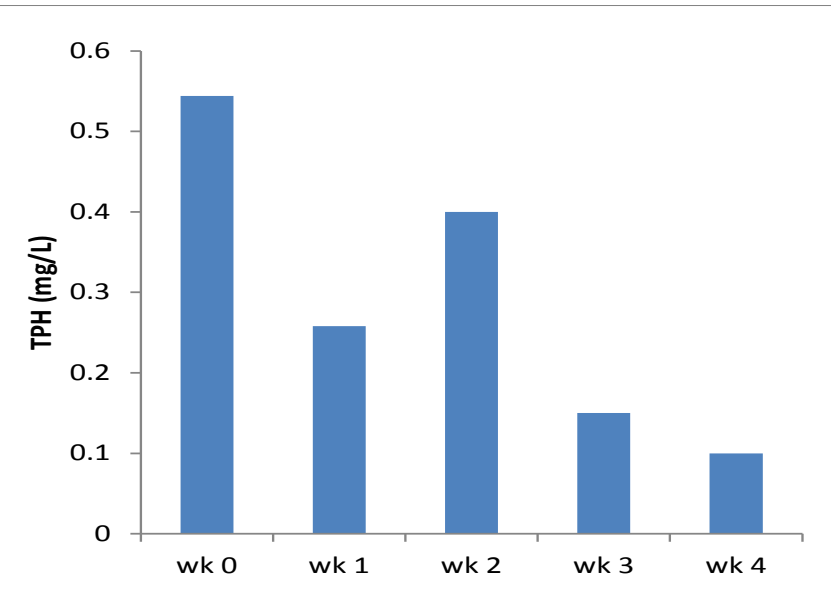

Figure 1.7: Bar chart of remediation progress of Shodeinde with $\mathrm{KMnO}_{4}$.

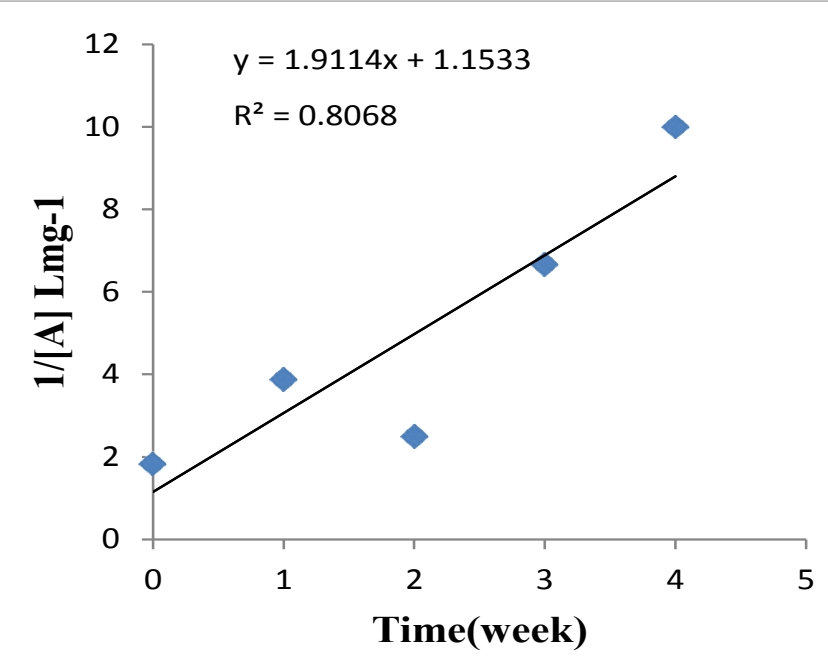

Figure 1.8: Graph of second order reaction of Shodeinde.

$\mathrm{R}^{2}=0.811, \mathrm{~K}=0.971$ week $^{-1}$

[A exp.] $=2.54 \mathrm{mg} / \mathrm{L},[$ A cal. $]=0.761 \mathrm{mg} / \mathrm{L}$

$\mathrm{T}_{1 / 2}=0.41$ week

$\mathrm{R}^{2}=0.937, \mathrm{~K}=3.218$ week $^{-1}$

[A exp.] $=0.271 \mathrm{mg} / \mathrm{L}$, [A cal.] $=0.430 \mathrm{mg} / \mathrm{L}$

$\mathrm{T}_{1 / 2}=1.15$ week

$\mathrm{R}^{2}=0.806, \mathrm{~K}=1.911$ week $^{-1}$

[A exp.] $=0.544 \mathrm{mg} / \mathrm{L}$, [A cal. $]=0.867 \mathrm{mg} / \mathrm{L}$

$\mathrm{T}_{1 / 2}=0.96$ week

\section{Conclusion}

The study revealed that all the wells contained TPH and are therefore polluted with petroleum hydrocarbon but at different concentrations. Even, the control (Jakande) also contained TPH. Geoenvironmental Engineering research group in Federal University of Technology Akure, Nigeria, had already pumped and skimmed off a large volume of petroleum hydrocarbon from the well before the samples were collected. The remediation of the wells with potassium permanganate followed a second order reaction. The graph of Oyewole and Kamilla followed the same pattern; their $\mathrm{R}^{2}$ were closer to one than Shodeinde and lasunferanmi. Also, their half-life was greater than one week. While, the half-life of Lasunferanmi and Shodeinde was less than one week; with Lasunferanmi, being the least, 0.41 week and shodeinde, 0.96 week.

\section{Acknowledgment}

This research was carried out through the funds given by TETFUND NATIONAL RESEARCH FUND (NRF) NIGERIA. The authors acknowledge the TETFUND National Research Fund of The Prof. S.A. Ola Research Group Federal University of Technology, Akure referenced TETF/ES/NRF/013/VOL.I for the Research Project titled "Site Remediation in Nigeria: Proven and Innovative Technologies, Recovery of Free Hydrocarbon from Soil/Groundwater.

\section{References}

1. Gray NF (1995) Drinking water quality; problems and solutions. John Wiley and Sons.

2. Mendie U (2005) The Nature of Water. The Theory and Practice of Clean Water Production for Domestic and Industrial Use. Lacto-Medals Publishers, Lagos, pp: 1-21.

3. Vanloon GW, Duffy SJ (2005) The Hydrosphere. Environmental Chemistry: A Global Perspective. New York: Oxford University Press, pp: 197-212.

4. NNPC (2009) Nigerian National Petroleum Corporation, Monthly Petroleum Information, September Lagos, Nigeria.

5. Ndubuisi OL, Asia IO (2007) Environmental Protection in Oil Producing Areas of the Niger-Delta Basin, Nigeria. Emperical Assessment of Trends and People's Perception. Environmental Research Journal 1: 18-26.

6. Opukri CO, Ibaba SI (2008) Oil induced Environmental Degradation and Internal Population Displacement in the Nigeria's Niger- Delta. Journal of sustainable Development in Africa, Volume 1.

7. Aaron KK (2006) Human Rights Violation and Environmental Degradation in the Niger-Delta. In: Elizabeth P, Baden O (eds.), Activating Human Rights, Oxford, Barne, New York, USA

8. Guardian (2004) Pipeline of pain, danger in Baruwa. The Guardian Newspaper, Thursday November 25.

9. APHA (1985) Standard Methods for Examination of Water and Wastewater 20th edn, American Public Health Association, Washington DC. 